\title{
Therapeutics
}

\section{Review: sildenafil improves sexual and erectile function in men}

Burls A, Gold L, Clark W. Systematic review of randomised controlled trials of sildenafil (Viagra) in the treatment of male erectile dysfunction. Br J Gen Pract 2001 Dec;51:1004-12.

\section{QUESTION: In men with erectile dysfunction (ED), is sildenafil effective for improving erectile or sexual function?}

\section{Data sources}

Studies were identified by searching Medline, EMBASE/ Excerpta Medica, the Cochrane Library, PsycLIT, the National Research Register, Pharmline, Science Citation Index, Premedline, and internet search engines in June 1999 using the terms sildenafil and Viagra. 8 journals were hand searched: BMJ, Lancet, JAMA New England Journal of Medicine, British Journal of General Practice, Drug, Inpharma, and Scrip. Reference lists of relevant studies and a Food and Drug Administration review were scanned. Pfizer Ltd and experts in the field were contacted.

\section{Study selection}

Published or unpublished randomised controlled trials (RCTs) in any language were selected if they compared sildenafil with a placebo or alternative treatment in men with ED.

\section{Data extraction}

2 reviewers independently assessed the quality of studies (ie, allocation concealment, blinding, losses to follow up, and intention to treat analysis) and extracted data. Discrepancies were resolved by discussion. When trials were published in abstract form only, further information was requested from Pfizer. The main outcome was sexual function (questions 3 and 4 of the International Index of Erectile Function [IIEF]; responses were rated on a 5 point scale with 0 indicating no attempt at intercourse).

\section{Main results}

21 RCTs met the selection criteria; 3 were published as full reports. 1 RCT compared sildenafil with an alternative compound. All RCTs were double blind and $>80 \%$ of patients completed the studies. Studies included approximately 4000 men who had had ED for $\geqslant 6$ months and were in stable relationships for $>6$ months. 8 RCTs (mean follow up $14 \mathrm{wks}$ ) showed that sildenafil (25-200 $\mathrm{mg}$ ) was better than placebo for increasing the frequency of penetration (IIEF question 3, range 3.2-4.0 for sildenafil and 1.9-2.3 for placebo, $\mathrm{p}<0.001$ for all RCTs) and improving maintenance of erection (IIEF question 4, range 2.9-3.9 for sildenafil and 1.6-2.1 for placebo, $\mathrm{p}<0.001$ for all RCTs). At a mean follow up of 10.8 weeks, more men on sildenafil than on placebo reported that treatment improved their erections $(16$ RCTs) (table).

\section{Conclusion}

In men with erectile dysfunction, sildenafil improves sexual and erectile function.

Sildenafil v placebo for erectile dysfunction*

\begin{tabular}{|c|c|c|c|c|}
\hline \multirow{2}{*}{$\begin{array}{l}\text { Outcome at mean } \\
10.8 \text { weeks }\end{array}$} & \multicolumn{2}{|c|}{ Weighted event rates } & \multirow[b]{2}{*}{$\mathrm{RBI}(95 \% \mathrm{Cl})$} & \multirow[b]{2}{*}{ NNT (Cl) } \\
\hline & Sildenafil & Placebo & & \\
\hline Improved erections & $75 \%$ & $21 \%$ & $257 \%(193$ to 334$)$ & 2 (2 to 3$)$ \\
\hline
\end{tabular}

*Abbreviations defined in glossary; weighted event rates calculated from data in article.

\section{COMMENTARY}

The long time lag between the search for trials and publication has unfortunately already rendered this well conducted systematic review by Burls et al outdated. A Medline search yielded 27 additional published RCTs of sildenafil in men who were of diverse races and had ED of different aetiologies. However, these additional trials do not refute the consistency or direction of effect of the main results of this systematic review. A number needed to treat of 2-3 for the main outcome measure from this review justifies sildenafil's place as the first line treatment for men with $\mathrm{ED}$.

This endorsement does not come without its caveats. The main concern, not sufficiently addressed in this systematic review because of the paucity of data, relates to its cardiovascular safety. The available evidence suggests that in patients who have cardiac disease and are not on nitrates, sildenafil does not provoke ischaemia during exercise, ${ }^{1}$ although sexual activity may still provoke adverse cardiac events. Clinicians prescribing the drug to men with known or suspected cardiac disease should adhere to recommendations aimed at minimising cardiovascular events. ${ }^{23}$ The dangers of combination with recreational drugs and issues pertaining to HIV prevention also need to be addressed.

In one open label extension trial, up to 52 weeks of treatment did not diminish the efficacy of sildenafil in patients with ED and it remained well tolerated, ${ }^{4}$ but more long term data are needed. Sildenafil is not an initiator of erections, and psychosexual counselling may need to be combined with sildenafil therapy to address misconceptions, interpersonal issues, and/or secondary psychological problems, irrespective of the aetiology of ED. In some settings, psychosexual counselling may in itself suffice to treat ED.

Regularly updated systematic reviews are required to keep pace with the rapid new developments in this field.

Prathap Tharyan, MD , MRCPsych Christian Medical College Vellore, Tamil Nadu, India

1 Arruda-Olson AM, Mahoney DW, Nehra A, et al. Cardiovascular effects of sildenafil during exercise in men with known or probable coronary artery disease: a randomized crossover trial. JAMA 2002;287:719-25.

2 Cheitlin MD, Hutter AM Jr, Brindis RG, et al. Use of sildenafil (Viagra) in patients with cardiovascular disease. Technology and Practice Executive Committee. Circulation 1999;99:168-77.

3 Marwick TH. Safe sex for men with coronary artery disease: exercise, sildenafil, and risk of cardiac events. JAMA 2002;287:766-7.

4 Steers W, Guay AT, Leriche A, et al. Assessment of the efficacy and safety of Viagra (sildenafil citrate) in men with erectile dysfunction during long-term treatment. Int J Impot Res 2001;13:261-7. 